\title{
Serum bioactive lysophospholipids prevent TRAIL- induced apoptosis via PI3K/Akt-dependent cFLIP expression and Bad phosphorylation
}

\author{
Y-C Kang ${ }^{1,4}$, K-M Kim $^{1,4}$, K-S Lee ${ }^{1}$, S Namkoong ${ }^{1}$, S-J Lee ${ }^{1}$, \\ J-A Han ${ }^{1}$, D Jeoung ${ }^{2}$, K-S Ha ${ }^{1}$, Y-G Kwon ${ }^{3}$ and Y-M Kim ${ }^{*, 1,2}$ \\ 1 Department of Molecular and Cellular Biochemistry, College of Medicine, \\ Kangwon National University, Chunchon, Kangwon-Do 200-701, Korea \\ 2 Vascular System Research Center, Kangwon National University, Chunchon, \\ Kangwon-Do 200-701, Korea \\ ${ }^{3}$ Department of Biochemistry, College of Science, Yonsei University, Seoul 120- \\ 749 , Korea \\ ${ }^{4}$ These authors contributed equally to this work \\ * Corresponding author: Y-M Kim, Department of Molecular and Cellular \\ Biochemistry, College of Medicine, Kangwon National University, Chunchon, \\ Kangwon-Do 200-701, Korea. Tel: + 8233250 8831; \\ Fax: + 8233244 3286; E-mail: ymkim@ kangwon.ac.kr
}

Received 14.8.03; revised 21.1.04; accepted 06.5.04; published online 06.8.04 Edited by $Y$ Tsujimoto

\section{Abstract}

Serum contains a variety of biomolecules, which play an important role in cell proliferation and survival. We sought to identify the serum factor responsible for mitigating tumor necrosis factor-related apoptosis-inducing ligand (TRAIL)induced apoptosis and to investigate its molecular mechanism. TRAIL induced effective apoptosis without serum, whereas bovine serum decreased apoptosis by suppressing cytochrome $c$ release and caspase activation. Indeed, albumin-bound lysophosphatidic acid (LPA) and sphingosine-1-phosphate (S1P) inhibited TRAIL-induced apoptosis by suppressing caspase activation and cytochrome $c$ release. LPA increased phosphatidylinositol 3-kinase (PI3K)-dependent Akt activation, cellular FLICE-inhibitory protein (cFLIP) expression, and Bad phosphorylation, resulting in inhibition of caspase-8 activation and Bad translocation to mitochondria. The antiapoptotic effect of LPA was abrogated by PI3K inhibitor, transfection with dominant-negative Akt, and specific downregulation of cFLIP expression using siRNA and further increased by siRNA-mediated suppression of Bad expression. Moreover, sera from ovarian cancer patients showed more protective effect against TRAIL-induced apoptosis than those from healthy donors, and this protection was suppressed by PI3K inhibitor. Our results indicate that albumin-bound LPA and S1P prevent TRAIL-induced apoptosis by upregulation of cFLIP expression and in part by Bad phosphorylation, through the activation of PI3K/Akt pathway. Cell Death and Differentiation (2004) 11, 1287-1298.

doi:10.1038/si.cdd. 4401489

Published online 6 August 2004

Keywords: cytochrome c; caspase; albumin-bound lysophosphatidic acid; mitochondria

\begin{abstract}
Abbreviations: TRAIL, tumor necrosis factor-related apoptosisinducing ligand; BSA, bovine serum albumin; dBSA, delipidated BSA; LPA, lysophosphatidic acid; S1P, sphingosine-1-phosphate; PI3K, phosphatidylinositol 3-kinase; cFLIP, cellular FLICE-inhibitory protein; WT-Akt, wild-type Akt; DN-Akt, dominant-negative Akt; FBS, fetal bovine serum; DEVDase, caspase3-like protease; IETDase, caspase-8-like protease; ActD, actinomycin D; DAPI, 4,6-diamidino-2-phenylindole; PTX, pertussis toxin
\end{abstract}

\section{Introduction}

Tumor necrosis factor (TNF)-related apoptosis-inducing ligand (TRAIL), ${ }^{1}$ also known as Apo-2 ligand, ${ }^{2}$ is a member of the TNF family of cytokines and is capable of inducing apoptosis in a wide variety of cancer cells in culture. The apoptosis-inducing receptors for TRAIL include the transmembrane type-I receptors, TRAIL-R1 (DR4) and TRAIL-R2 (DR5). These receptors are expressed on the surface of many types of tumor cells and transmit apoptotic signals via cytoplasmic death domains. However, TRAIL also binds to the nonapoptosis-inducing decoy receptors, DcR1 and DcR2, which are truncated TRAIL receptors in which the cytoplasmic regions containing death domains are deleted.

Recombinant human TRAIL protein preferentially induces apoptosis of tumor cells but not in most types of untransformed cells. ${ }^{3}$ However, not all tumors respond to TRAIL. This lack of response may be attributed either to an unfavorable ratio of death receptors to decoy receptors or to other intracellular resistance mechanisms. ${ }^{4}$ With respect to intracellular mechanisms, several intracellular antiapoptotic molecules including antiapoptotic $\mathrm{Bcl}-2$ family proteins, IAPs, and cellular FLICE-inhibitory protein (cFLIP) inhibit the apoptotic signaling cascade ${ }^{5-7}$ through the inhibition of mitochondrial cytochrome $c$ release, apoptosome formation, and recruitment of procaspase-8 to the receptor death domain. Furthermore, extracellular peptide growth factors (plateletactivating factor and epidermal growth factor) and cytokines including interleukin- $1 \beta$ have been shown to protect cells from TRAIL-induced apoptosis by activating a protective intracellular signal. ${ }^{8,9}$ These factors are usually present in serum, but most of these serum factors occur at concentrations far below those necessary to elicit their survival effects. However, recent studies showed that some cells including hepatocytes are sensitive to TRAIL-induced apoptosis in vitro without serum, ${ }^{10}$ but resistant with even low concentrations of serum. ${ }^{11}$ These evidences suggest that other survival factors against TRAIL-induced apoptosis are present in serum, and these factors have not been characterized.

The lysophospholipid mediators, lysophosphatidic acid (LPA) and sphingosine-1-phosphate (S1P), are potent 
bioactive lipids, which are synthesized from phospholipids in platelets, fibroblasts, adipocytes, and tumor cells and then secreted into biological fluids. LPA and S1P occur normally in serum and bind with high affinity to albumin, while retaining their biological activities. ${ }^{12}$ Although these molecules exist in serum at concentrations of $2-20 \mu \mathrm{M},{ }^{13}$ their serum levels become increased in tumor-bearing patients. ${ }^{14}$ LPA and S1P have been shown to have pleiotropic functions such as mitogenesis and angiogenesis. In addition, they promote cell survival through activation of specific G-protein-coupled transmembrane receptors encoded by endothelial differentiation genes (EDG). LPA is predominantly bound to EDG2, EDG4, and EDG7, while S1P specifically binds to EDG1, EDG3, EDG5, EDG6, and EDG8. ${ }^{15}$ Following G-protein activation, one of the resulting intracellular signaling events is the activation of the lipid kinase phosphatidylinositol 3kinase (PI3K) and its downstream kinase Akt. ${ }^{16}$ Activated Akt phosphorylates Bad, procaspase-9, forkhead, CREB, and $\mathrm{IKK},{ }^{17}$ resulting in the suppression of the apoptotic signal cascade or expression of antiapoptotic genes.

We hypothesized that phospholipids could prevent TRAILinduced tumor cell death by altering expression and activation of critical molecules in apoptotic signal transduction. We here identified albumin-bound LPA and S1P as two serum survival factors that protect cells from TRAIL-induced apoptosis. LPA activates the PI3K/Akt signaling pathway and subsequently increases cFLIP expression and Bad phosphorylation, which lead to the inhibition of caspase activation and mitochondrial cytochrome $c$ release. These results indicate that albuminbound LPA and S1P are lipid-based survival factors in serum, thus suggesting that control of the serum LPA and S1P levels may be important for in vivo TRAIL-mediated cancer therapy.

\section{Results}

\section{Serum and albumin protect tumor cells from TRAIL-induced apoptosis}

To examine the effects of serum on TRAIL-induced tumor cell apoptosis, we treated HeLa cells with TRAIL $(100 \mathrm{ng} / \mathrm{ml})$ in the presence or absence of various fetal bovine serum (FBS) concentrations and determined cell viability by crystal violet staining after $8 \mathrm{~h}$. TRAIL induced apoptotic cell death in $\sim 60 \%$ of cells in the absence of FBS, and this apoptosis was suppressed in a dose-dependent manner by the addition of FBS (Figure 1a). A similar result was observed when FBS was replaced by corresponding concentrations of calf serum (data not shown). To characterize a survival factor of serum, we removed low-molecular-weight components of serum by dialysis using a membrane with a $12 \mathrm{kDa}$ molecular cutoff and examined the effect of dialyzed serum on apoptosis induced by TRAIL. Dialyzed serum exhibited the same protective effect as nondialyzed serum (Figure 1b). Albumin is a major component of serum and plays a role as a carrier of bioactive lipids. ${ }^{18}$ Therefore, we next examined the protective effects of bovine serum albumin (BSA) and delipidated BSA (dBSA) on TRAIL-induced apoptosis. BSA suppressed the apoptotic cell death, while dBSA failed to do so (Figure $1 \mathrm{~b}$ ). In addition, the serum albumins prepared from rat, horse, and human showed similar antiapoptotic effect (data not shown), indicating that the protective effects of albumin are not species specific. Similar protective effects were observed in the colon cancer cell line DLD-1 (Figure 1c). These results suggest that albumin-bound lipid component(s) may be responsible for prevention against TRAIL-induced apoptosis.
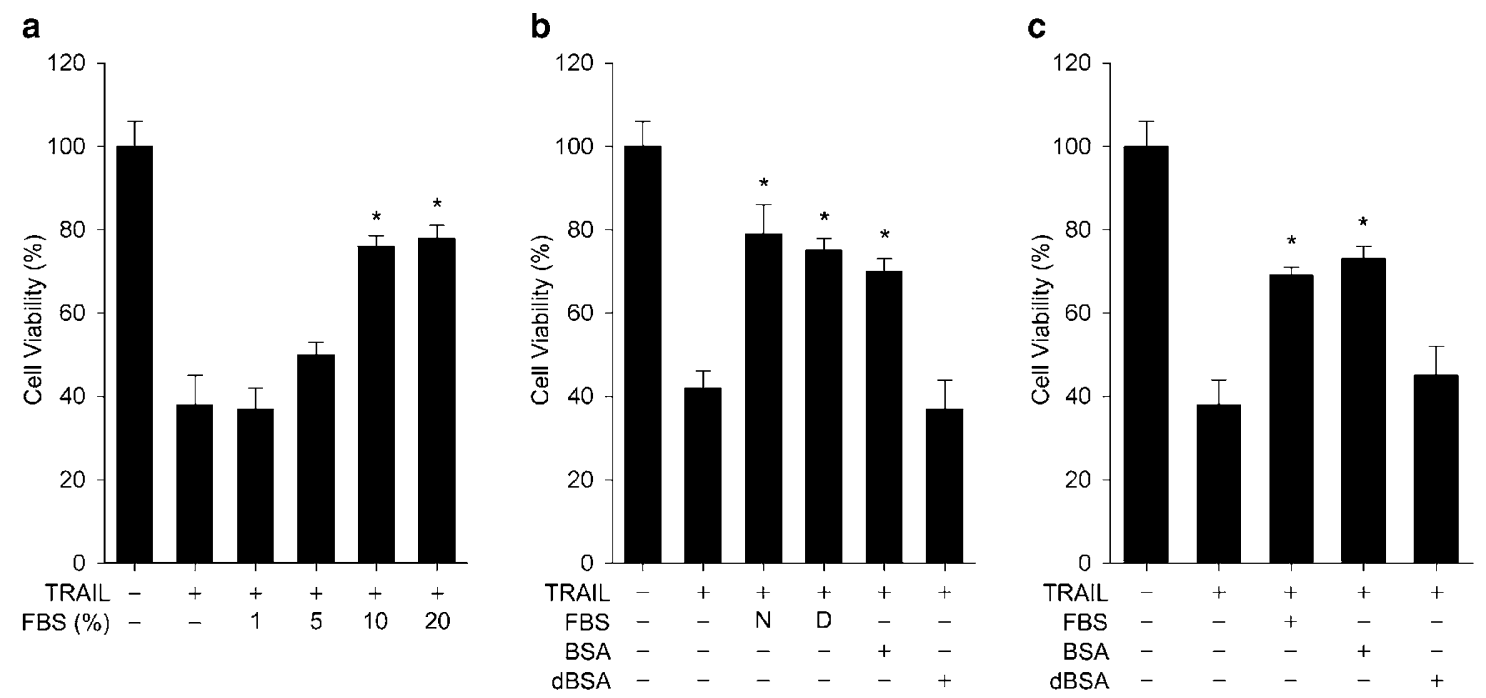

Figure 1 Effect of FBS and BSA on TRAIL-induced apoptosis. Cells plated in 12-well dishes at a density of $1 \times 10^{6}$ cells/ml were cultured for $8 \mathrm{~h}$ in $10 \%$ FBS containing DMEM and further cultured in the serum-free medium for another $6 \mathrm{~h}$. (a) HeLa cells were treated with TRAIL (100 ng/ml) in the presence or absence of FBS. (b) HeLa cells were treated with TRAIL $(100 \mathrm{ng} / \mathrm{ml})$ in the presence of $10 \%$ nondialyzed (N) or dialyzed FBS (D), $5 \%$ BSA, or $5 \%$ dBSA. (c) DLD-1 cells were treated with TRAIL $(100 \mathrm{ng} / \mathrm{ml})$ in the presence of $10 \% \mathrm{FBS}, 5 \% \mathrm{BSA}$, or $5 \% \mathrm{dBSA}$. After $8 \mathrm{~h}$ of these treatments, cell viability was measured by crystal violet staining. Data represent the mean \pm S.D. of more than three independent experiments. ${ }^{*} P<0.01$ versus TRAlL alone 


\section{LPA and S1P are bioactive molecules responsible for serum antiapoptotic factors}

Albumin transports multiple substances within the bloodstream to and from tissues, including phospholipids such as LPA and S1P. ${ }^{19,20}$ LPA and S1P are thought to be involved in many biological activities including mitogenesis and proliferation of cells. ${ }^{21}$ We thus determined whether LPA and S1P act as antiapoptotic factors that accounted for the cytoprotective activity of serum and albumin. HeLa cells were treated with TRAIL in the presence of free LPA $(4 \mu \mathrm{M})$ or S1P $(0.4 \mu \mathrm{M})$, and cell viability was measured after $8 \mathrm{~h}$ incubation. These free LPA and S1P effectively protected cells from TRAIL-induced apoptosis (Figure 2a). We next examined the preventive effect of dBSA-LPA or dBSA-S1P on TRAIL-induced apoptosis. dBSA-LPA prevented TRAIL-induced apoptosis in a dose-dependent manner, with maximal protection observed at $4 \mu \mathrm{M}$. Additionally, $0.4 \mu \mathrm{M}$ of $\mathrm{dBSA}-\mathrm{S} 1 \mathrm{P}$ also prevented apoptotic cell death (Figure $2 b$ ). FBS, BSA, dBSA-LPA, and dBSA-S1P, but not dBSA alone, significantly inhibited TRAILinduced DNA fragmentation characteristic of typical apoptosis (Figure 2c). Furthermore, HeLa cells undergoing TRAILmediated cell death displayed typical apoptotic features, including chromatin condensation, nuclear pyknosis, and in some cases nuclear fragmentation (Figure 2d, ii, arrow). These morphological changes were decreased by cotreatment with FBS, BSA, dBSA-LPA, or dBSA-S1P, but not by dBSA alone (Figure 2d, iii-vii). These results indicate that LPA and S1P are likely to be important factors responsible for the survival effect of FBS.

\section{LPA suppresses the activation of caspase-3 and -8 induced by TRAIL}

Caspase activity and cytochrome $c$ release are known to be one of the major events in apoptotic tumor cells. ${ }^{22}$ Treatment of HeLa cells with TRAIL increased caspase-8-like (IETDase) and caspase-3-like (DEVDase) activities more than eight-fold, and these increases were significantly inhibited by FBS and BSA (Figure $3 a$ and b). As expected, dBSA-LPA and dBSAS1P inhibited these enzyme activities; however, dBSA itself did not. All caspases are constitutively present as zymogens in cells and become proteolytically cleaved into their active forms when cells are stimulated with apoptogenic stimuli. ${ }^{23}$ We next determined whether the inhibitory effect of
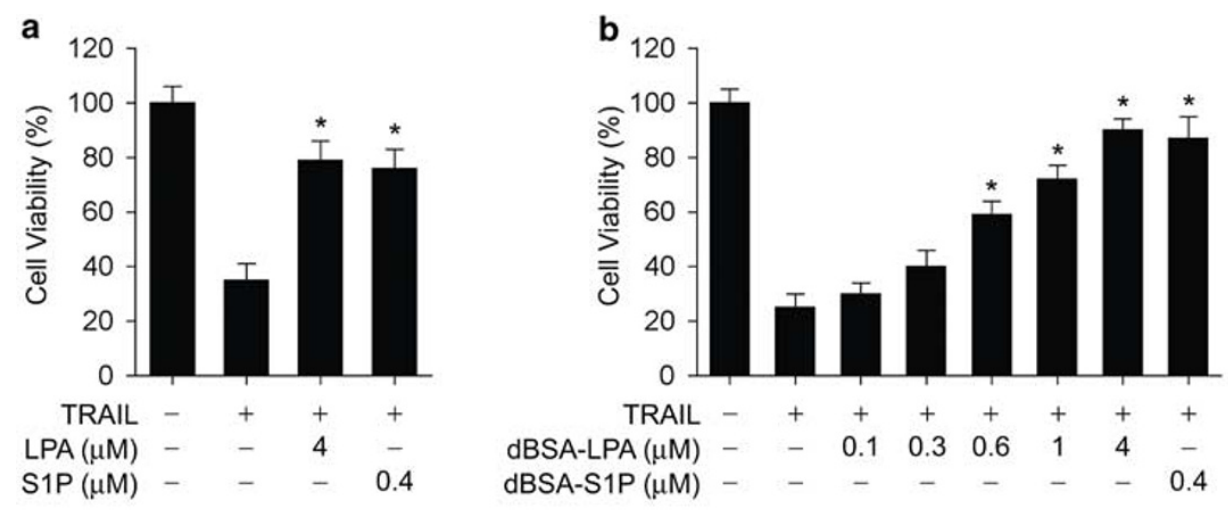

c

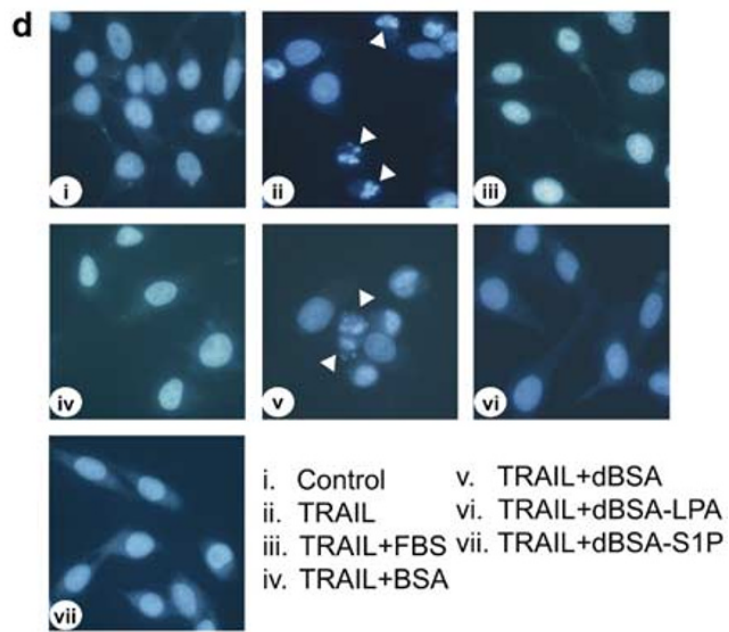

Figure 2 LPA and S1P prevent TRAIL-induced HeLa cell apoptosis. (a) HeLa cells were treated with TRAIL ( $100 \mathrm{ng} / \mathrm{ml})$ in the presence of LPS or S1P for $8 \mathrm{~h}$, and cell viability was measured by the crystal violet staining method. Data represent the mean \pm S.D. of four independent experiments. ${ }^{\star} P<0.01$ versus TRAlL alone. (b) Cells were treated TRAIL in the presence of dBSA-LPA or dBSA-S1P for $8 \mathrm{~h}$, and cell viability was measured by the crystal violet staining method. Data represent the mean \pm S.D. of four independent experiments. ${ }^{*} P<0.01$ versus TRAlL alone. Cells were treated with TRAIL ( $\left.100 \mathrm{ng} / \mathrm{ml}\right)$ in the presence of $10 \%$ FBS, $5 \%$ BSA, $5 \%$ $\mathrm{dBSA}, 4 \mu \mathrm{M}$ dBSA-LPA, or $0.4 \mu \mathrm{M}$ dBSA-S1P. (c) After $5 \mathrm{~h}$, DNA was isolated from cells treated as indicated, and DNA fragmentation was determined by agarose gel electrophoresis. (d) After $5 \mathrm{~h}$, changes of nuclear morphology were assessed by DAPI staining 


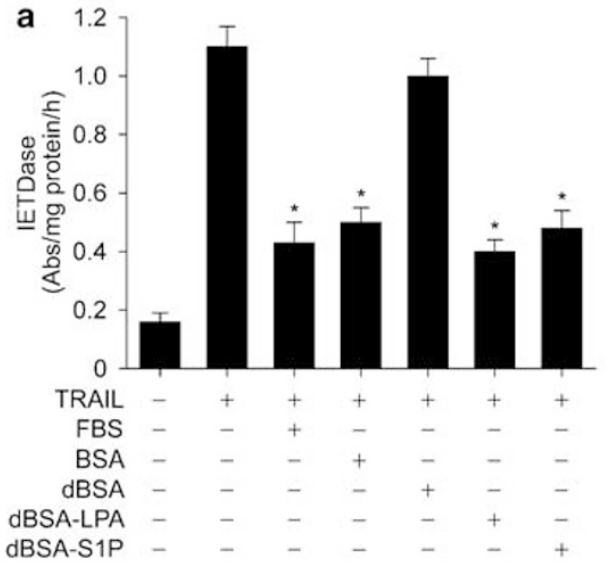

dBSA-S1P

C

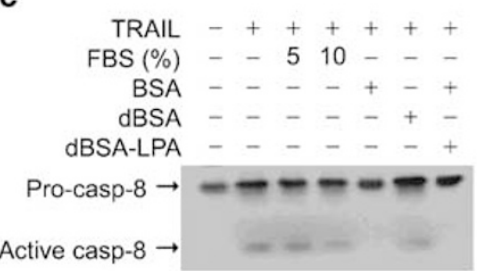

d

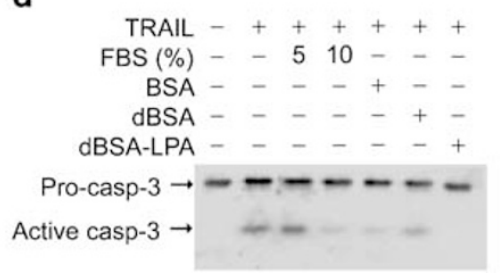

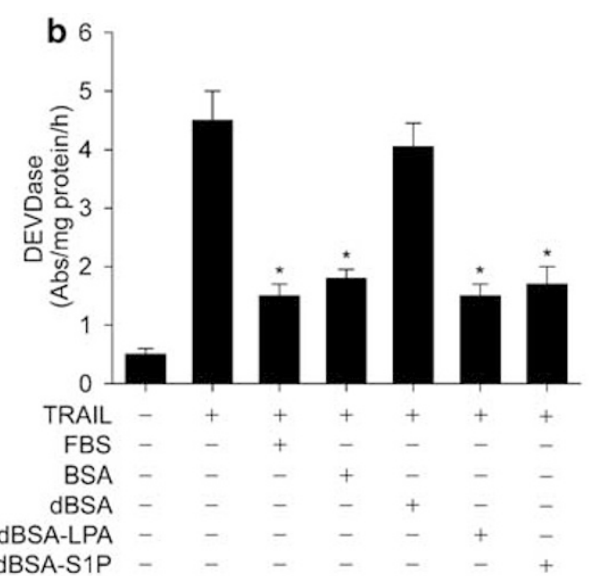

e

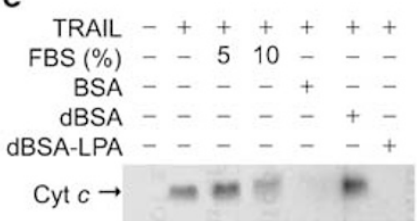

Figure 3 dBSA-LPA and dBSA-S1P suppress caspase-8 and -3 activities and cytochrome $c$ release induced by TRAIL. HeLa cells were treated with TRAIL in the presence of $10 \% \mathrm{FBS}, 5 \% \mathrm{BSA}, 5 \% \mathrm{dBSA}, 4 \mu \mathrm{M}$ dBSA-LPA, or $0.4 \mu \mathrm{M}$ dBSA-S1P. After $5 \mathrm{~h}$, cells were harvested and lysed by three cycles of freeze and thaw. Activities of caspase-8 (a) and caspase-3 (b) were determined by colorimetric assays using the chromogenic substrates $240 \mu \mathrm{M}$ Ac-IETD-pNA (caspase-8-like activity) and $150 \mu \mathrm{M}$ Ac-DEVD-pNA (caspase-3-like activity), respectively. Data shown are the mean \pm S.D. of more than three independent experiments. ${ }^{*} P<0.01$ versus TRAIL alone. (c, d) Cytosolic proteins were separated by SDS-PAGE and protein bands were detected by Western blot analyses using antibodies specific for caspase-8 and -3. (e) For cytochrome $c$ release, cells were harvested after $4 \mathrm{~h}$ incubation and homogenized in an isotonic sucrose solution using a Dounce homogenizer. Cytosolic fractions were obtained after centrifugation at $12000 \times g$ for $20 \mathrm{~min}$ at $4^{\circ} \mathrm{C}$. Cytosolic cytochrome $c$ was determined by Western blot analysis using an antibody for cytochrome $c$

dBSA-LPA on apoptotic cell death is associated with the suppression of caspase activation. Western blot analyses confirmed the appearance of active fragments of caspase- 8 and -3 in the TRAIL-treated cells, and this activation was suppressed by cotreatment with FBS, BSA, or IBSA-LPA, but not by $\mathrm{dBSA}$ alone (Figure $\mathrm{Bc}$ and $\mathrm{d}$ ). Mitochondrial cytochrome $c$ release into the cytosol, which is an apoptotic signaling event that occurs between activation of caspase-8 and $-3,{ }^{22}$ was observed after treatment with TRAIL. However, redistribution of cytochrome $c$ was suppressed by the addition of FBS, BSA, or dBSA-LPA, but not by dBSA (Figure $3 e$ ). These results suggest that LPA inhibits the activation of proximal caspase- 8 and mitochondrial cytochrome $c$ release during TRAIL-induced apoptotic signaling.

\section{LPA activates PI3K-dependent Akt}

Activation of the lipid kinase PI3K and its downstream effector Akt has been shown to suppress apoptosis and promote cell survival. ${ }^{24-26}$ To explore whether LPA may suppress apoptosis and apoptotic signaling via the activation of the PI3K/Akt pathway, we examined the functional involvement of PI3K/Akt pathway in LPA-mediated cell survival. The PI3K inhibitors Wortmannin and LY294002 markedly inhibited the antiapoptotic effect of dBSA-LPA (Figure 4a). Activation of Akt is known to be a downstream mediator of PI3K in the survival signal cascade. ${ }^{24,25}$ Since phosphorylation of Akt at Ser-473 is required for its full activation, ${ }^{26}$ we examined the phosphory- lation status of endogenous Akt using an antibody that specifically recognizes Akt phosphorylated at Ser-473. Incubation of cells with dBSA-LPA or FBS resulted in phosphorylation of endogenous Akt, and this activation was markedly inhibited by LY294002 or Wortmannin (Figure 4b). Because LPA can activate PI3K via the $\beta \gamma$ subunits of $G_{i}$ in COS cells ${ }^{27}$ and Schwann cells, ${ }^{28}$ we examined whether this pathway is activated by LPA treatment in HeLa cells. Phosphorylation of Akt by LPS was inhibited by pretreatment of HeLa cells with pertussis toxin (PTX) (Figure 4c). These data indicate that the PTX-sensitive $G_{i / o}$ coupled to LPAspecific G-protein-coupled EDG2 may be involved in LPAmediated activation of the PI3K/Akt pathway. As the activation of PI3K/Akt survival pathway has been shown to inhibit caspase activation/activity, ${ }^{25,29}$ we examined whether PI3K inhibitor regulates the suppressive effect of LPA on DEVDase activity. Treatment with LY294002 or Wortmannin reversed the suppressive effect of dBSA-LPA on caspase activity (Figure 4d). These results indicate that the antiapoptotic effects of LPA involve the activation of the PI3K/Akt pathway in HeLa cell apoptosis induced by TRAIL.

\section{LPA increases Bad phosphorylation and cFLIP expression}

Since activation of Akt inhibits apoptosis by phosphorylating $\mathrm{Bad},{ }^{25}$ cells were incubated with dBSA-LPA in the presence or 

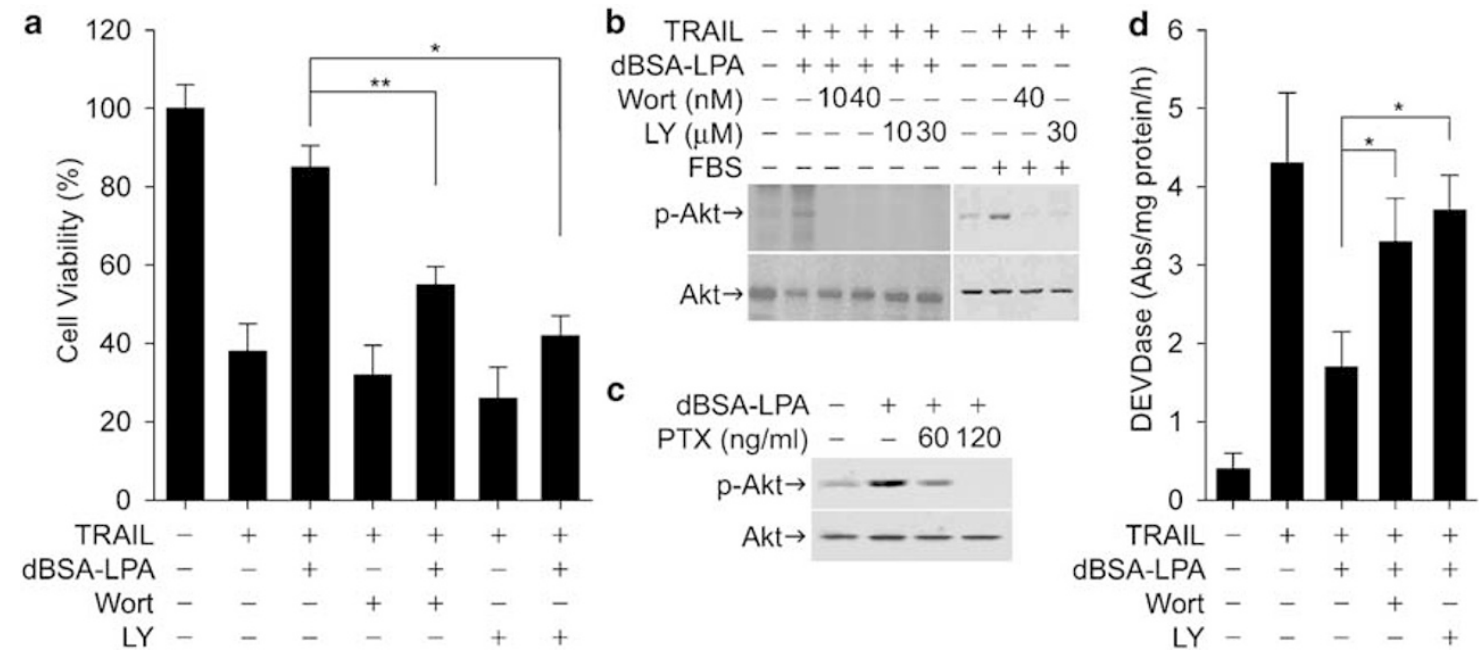

Figure 4 dBSA-LPA and FBS prevent TRAIL-induced HeLa cell apoptosis by PI3K-dependent Akt activation. HeLa cells were cotreated with TRAIL and FBS (10\%) or dBSA-LPA $(4 \mu \mathrm{M})$ in the presence or absence of Wortmannin (Wort, $40 \mathrm{nM})$, LY294002 (LY, $30 \mu \mathrm{M})$, or pertussis toxin (PTX, $60 \mathrm{and} 120 \mathrm{ng} / \mathrm{ml})$. (a) After $8 \mathrm{~h}$, cell viability was determined by crystal violet staining. (b, c) After 40 min incubation, cells were collected and cell lysates were prepared by three cycles of freeze and thaw and centrifugation at $12000 \times \mathrm{g}$ for $20 \mathrm{~min}$. Akt activation was determined by Western blot analyses using antibodies for phospho-Akt and Akt. (d) After $5 \mathrm{~h}$, DEVDase activity was determined by colorimetric assay using the chromogenic substrate Ac-DEVD-pNA (150 $\mu \mathrm{M})$. Data shown in (a) and (d) are the mean \pm S.D. of more than three independent experiments. ${ }^{*} P<0.01$ and ${ }^{* *} P<0.05$

a

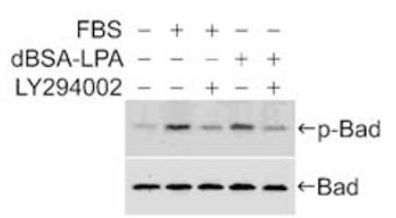

C

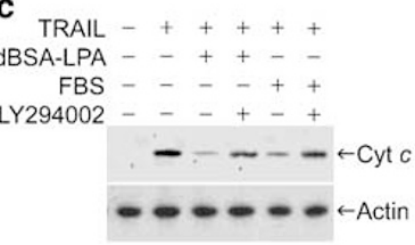

b
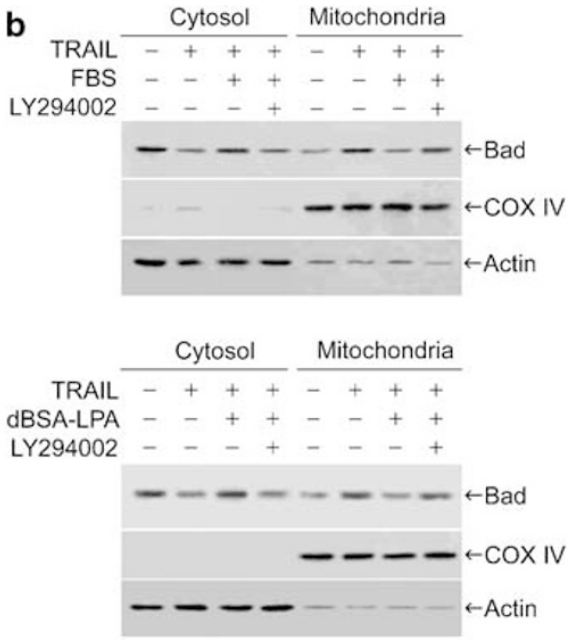

Figure 5 FBS and dBSA-LPA increase Bad phosphorylation and suppress cytochrome $c$ release induced by TRAIL. HeLa cells were treated with TRAIL (100 ng/ml) and FBS $(10 \%)$ or dBSA-LPA $(4 \mu \mathrm{M})$ in the presence or absence of LY294002 $(30 \mu \mathrm{M})$ for $90 \mathrm{~min}$. (a) Cells were harvested and lysed by three cycles of freeze and thaw. Cytosolic fractions were obtained by centrifugation at $12000 \times \mathrm{g}$ for $20 \mathrm{~min}$. Cytosolic proteins were separated by SDS-PAGE. Bad phosphorylation and Bad protein were determined by Western blot analyses using specific antibodies for phospho-Bad and Bad. (b) Cells were homogenized in a Dounce homogenizer with a loose pestle and fractionated into cytosol from the mitochondrial fraction. Localization of Bad was determined by Western blot analysis with anti-Bad antibody. Equally loaded proteins of the cytosolic fraction and the mitochondrial pellet were controlled using antibodies against actin and cytochrome coxidase subunit IV (Cox IV), respectively. (c) For cytochrome $c$ release, cells were harvested after $4 \mathrm{~h}$ incubation and homogenized in an isotonic sucrose solution using a Dounce homogenizer. Cytosolic fractions were obtained after centrifugation at $12000 \times g$ for $20 \mathrm{~min}$ at $4^{\circ} \mathrm{C}$. Cytosolic cytochrome $c$ was determined by Western blot analysis using an antibody for cytochrome $c$

absence of LY294002 for 90 min, and Bad phosphorylation was determined using an antibody specific to phosphorylated Bad at Ser-136. FBS and dBSA-LPA increased Bad phosphorylation, and this phosphorylation was suppressed by LY294002 (Figure 5a). One possible mechanism by which Akt signaling suppresses apoptosis is associated with the inhibition of cytochrome $c$ release by phosphorylating proapoptotic Bad and blocking its translocation into mitochondria from the cytosol. ${ }^{30}$ Phosphorylation of Bad can couple survival signals to extrinsic death pathway ${ }^{31}$ as well as intrinsic death machinery. ${ }^{32}$ We therefore examined the effects of FBS and dBSA-LPA on intracellular localization of Bad and cytochrome $c$ release by Western blot analysis. TRAIL increased the translocation of cytosolic Bad to mitochondria compared with control, and this translocation was suppressed by treatment with FBS or dBSA-LPA. The suppressive effects of FBS and dBSA-LPA on cytochrome $c$ redistribution were reversed by LY294002 (Figure 5b). Moreover, the inhibitory effects of FBS 
and ABSA-LPA on TRAIL-induced cytochrome $c$ release were reversed by treatment with LY294002 (Figure 5c). These results suggest that Bad phosphorylation by LPA-mediated PI3K/Akt activation prevents, in part, apoptotic cell death induced by TRAIL.

\section{LPA increases cFLIP expression and inhibits caspase- 8 activation}

It has also been shown that Akt blocks apoptotic cell death by increasing cFLIP expression, which inhibits caspase-8 activation by interfering with the recruitment of procaspase-8 to Fasassociated protein with a death domain. ${ }^{6,33}$ We further examined the effect of dBSA-LPA on the expression level of cFLIP and caspase-8 activation. Incubation of cells with BSA and dBSA-LPA increased the protein levels of cFLIP as FBS did, and these increases were suppressed by LY294002 (Figure 6a). Furthermore, the transcription inhibitor actinomycin D (ActD) decreased the increased cFLIP level by dBSALPA (Figure $6 \mathrm{~b}$ ) and increased caspase-8 activation/activity (Figure 6c). Taken together, these results suggest that dBSALPA may prevent TRAIL-induced apoptosis by PI3K/Akt pathway-dependent increase in cFLIP expression and subsequent inhibition of caspase-8 activation.

\section{Akt activation and cFLIP expression are required for the protective effects of serum and LPA against apoptosis}

To further determine the role of Akt in antiapoptotic signaling elicited by serum and LPA, the protective effects of serum and dBSA-LPA on HeLa cells stably transfected with dominantnegative Akt (DN-Akt) were compared with their effects on control cells transfected with an empty vector (pcDNA3) or cells overexpressing wild-type Akt (WT-Akt) (Figure 7a). These transfectant cells were treated with TRAIL in the presence or absence of FBS or dBSA-LPA, and cell survival was determined after $8 \mathrm{~h}$. When cells were cultured without
FBS or dBSA-LPA, TRAIL-induced apoptosis was partially decreased in WT-Akt-overexpressing cells, but slightly increased in DN-Akt-expressing cells, compared with control cells (Figure 7b). As expected, treatment with FBS or dBSALPA significantly blocked TRAIL-induced apoptosis in cells transfected with empty vector or WT-Akt, but not in DN-Aktexpressing cells, compared with cells cultured without them. The potential role of Akt in antiapoptotic effects of FBS and dBSA-LPA was further examined by measuring caspase-8like IETDase activity in these transfectant cells. FBS and dBSA-LPA significantly reduced the increased IETDase activity by TRAIL both in control and WT-Akt-transfected cells, but not effectively in DN-Akt-expressing cells (Figure 7c). To further evaluate whether the increased cFLIP level affects the protective effect of serum or dBSA-LPA, we transfected HeLa cells with pcDNA3-cFLIP and examined the effect of cFLIP overexpression on apoptotic cell death. Cells transfected with pcDNA3-cFLIP increased the cellular cFLIP protein level, while empty vector-transfected cells expressed the same level of cFLIP as that of control cells, as determined by Western blot analysis (Figure 7d). cFLIP-overexpressing cells significantly suppressed TRAIL-induced apoptosis and IETDase activity compared with empty vector-transfected cells (Figure 7e and f). dBSA-LPA inhibited IETDase activity and apoptotic cell death in both cells. These results suggest that serum and LPA protect cells from TRAIL-induced apoptosis by activating Akt-dependent signal pathway and that albumin-bound LPA may be an important factor for antiapoptotic effect of serum.

\section{siRNAs for CFLIP and Bad reversed serum- mediated protection against TRAIL-induced cell death}

To test whether cFLIP expression and Bad phosphorylation are necessary targets for serum- and LPA-induced protection against TRAIL-induced apoptosis, an siRNA approach was employed. Transfection with cFLIP siRNA reduced cFLIP

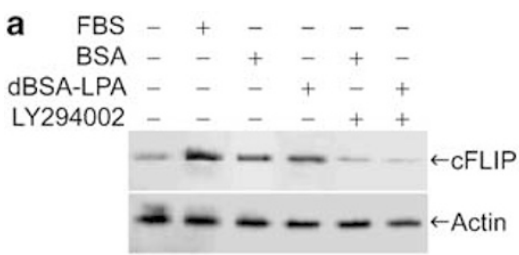

b

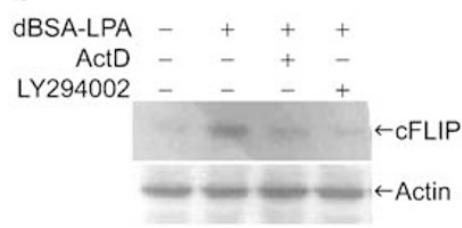

C

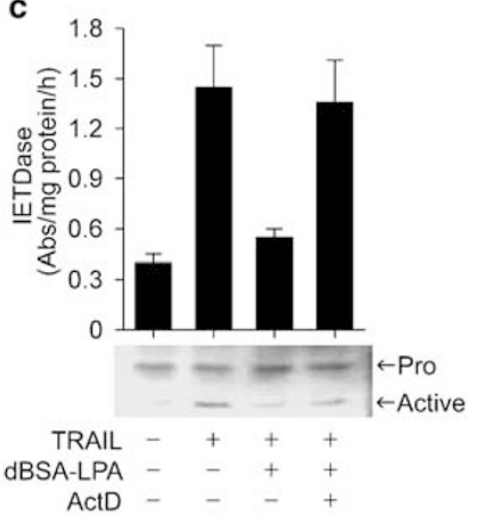

Figure 6 dBSA-LPA increases cFLIP expression and inhibits caspase-8 activation. (a) HeLa cells were treated with FBS (10\%), BSA (5\%), or dBSA-LPA (4 $\mu \mathrm{M}$ ) in the presence or absence of LY294002 $(30 \mu \mathrm{M})$. Cells were harvested and lysed by three cycles of freeze and thaw. Cytosolic fractions were obtained by centrifugation at $12000 \times g$ for $20 \mathrm{~min}$. Cytosolic proteins were separated by SDS-PAGE. cFLIP was determined by Western blot analyses using a specific antibody for cFLIP. (b) Cells were treated with dBSA-LPA $(4 \mu \mathrm{M})$ in the presence or absence of ActD $(80 \mathrm{ng} / \mathrm{ml})$ and LY294002 $(30 \mu \mathrm{M})$ for $90 \mathrm{~min}$. cFLIP expression was determined by Western blot analysis. (c) Cells were treated with TRAlL $(100 \mathrm{ng} / \mathrm{ml})$ in the presence of dBSA-LPA $(4 \mu \mathrm{M})$ or Act-D $(80 \mathrm{ng} / \mathrm{ml})$. After $5 \mathrm{~h}$, cells were harvested and lysed by three cycles of freeze and thaw. Caspase-8 activity and activation were measured by colorimetric assay using Ac-IETD-pNA and Western blot analysis 
a
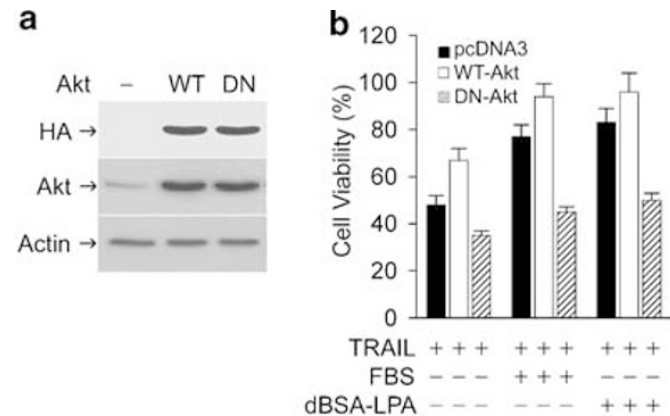

d

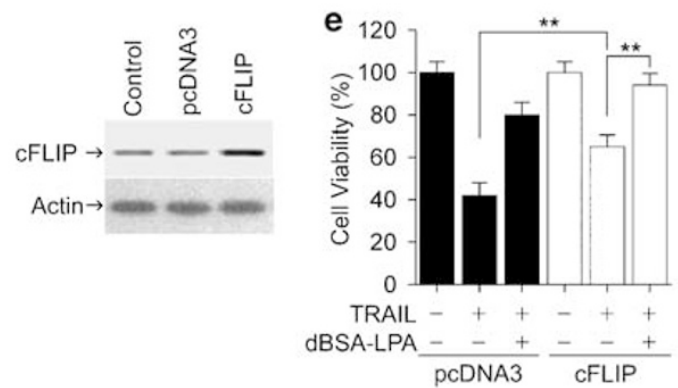

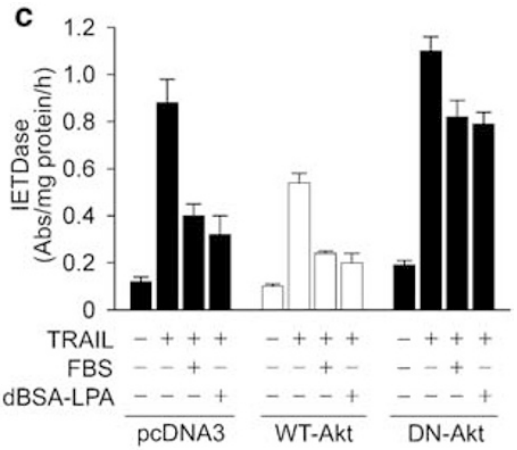

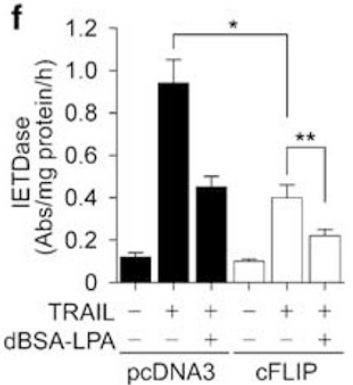

Figure 7 Akt activation and cFLIP expression are required for the protective effects of serum and LPA against apoptosis. HeLa cells were transfected with WT-Akt, DNAkt, cFLIP, or empty vector (pcDNA3) by the lipofectamine method. The stable transfectant clones with high expression of the target genes were selected by culturing with G418 $(800 \mu \mathrm{g} / \mathrm{ml})$. Cells were treated with TRAIL in the presence or absence of FBS $(10 \%)$, dBSA-LPA $(4 \mu \mathrm{M})$, or ActD $(80 \mathrm{ng} / \mathrm{ml})$. Expression levels of Akt (a) and cFLIP (d) were determined by Western blot analysis. (b, e) Cell viability was determined by crystal violet staining. (c, $\mathbf{f}$ ) IETDase activity was measured in the cytosolic fraction by colorimetric assay using Ac-IETD-pNA. Data shown are the mean \pm S.D. of more than three independent experiments. ${ }^{*} P<0.01$ and ${ }^{* \star} P<0.05$

expression (Figure 8a). Downregulation of cFLIP expression was found to decrease significantly the protective effect of serum and LPA against TRAIL-induced apoptosis and further increase TRAIL-induced apoptosis in the absence of serum and dBSA-LPA (Figure 8b). In addition, transfection with Bad siRNA suppressed Bad expression and total Bad phosphorylation compared with the untransfected control (Figure 8c) and further prevented HeLa cells from TRAIL-induced apoptosis in the presence or absence of serum or dBSALPA (Figure 8d). These results indicate that cFLIP and Bad are both important targets of LPA survival signaling against TRAIL-induced apoptosis.

\section{Sera from ovarian cancer patients show more preventive effect against TRAIL-induced cell death than those of healthy donors}

Ovarian cancer cells constitutively synthesize and release significant amounts of $\mathrm{LPA}^{34}$ and LPS concentration is significantly higher in sera from ovarian cancer patients than those from healthy donors. ${ }^{35}$ We prepared sera from 12 ovarian cancer patients and 12 healthy female donors. To examine the effect of the human sera on apoptotic cell death, we treated HeLa cells with TRAIL in the presence or absence of these sera and determined cell viability by clonogenic assay after $8 \mathrm{~h}$ (Figure 9). Sera from patients with ovarian cancer showed more protective effect against TRAIL-induced apoptosis than those from healthy donors, and this protection was suppressed by the PI3K inhibitor Wortmannin. The addition of $1 \mu \mathrm{M}$ LPA to the healthy sera increased their protective effects, which was comparable to those of the cancer patient sera. These results suggest that some tumors may protect themselves from TRAIL-mediated apoptosis, probably by synthesizing bioactive lipid mediators such as LPA and S1P.

\section{Discussion}

This study was undertaken to identify serum factors inhibiting TRAIL-induced apoptosis. We found that serum and the major protein in bovine serum, BSA, but not dBSA, prevented TRAIL-induced apoptosis. This indicates that the antiapoptotic factor of serum is likely to be lipid component(s) bound to albumin, but not albumin itself. Indeed, we found that the bioactive lysophospholipids LPA and S1P, which occur normally in serum and bind with high affinity to albumin, suppressed HeLa cell apoptosis induced by TRAIL through the inhibition of activation of caspase- 8 and -3 , mitochondrial cytochrome $c$ release, and DNA fragmentation. This protective effect was associated with PI3K/Akt-dependent increases in cFLIP expression and Bad phosphorylation, which are responsible for the suppression of caspase-8 activation and mitochondrial cytochrome $c$ release, respectively. However, the antiapoptotic effect of LPA was abrogated by PI3K inhibitor, transfection with DN-Akt, and specific downregulation of cFLIP expression using siRNA. The protective effect of LPA was further increased by siRNA-mediated suppression of 
a

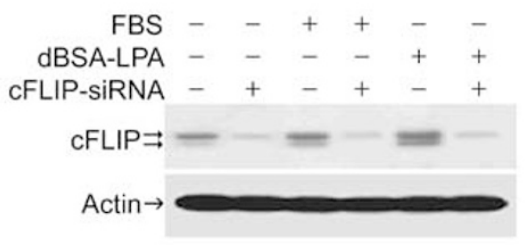

b

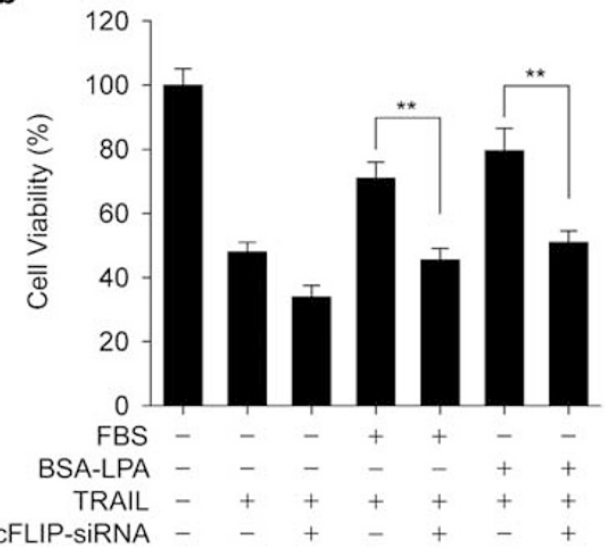

C

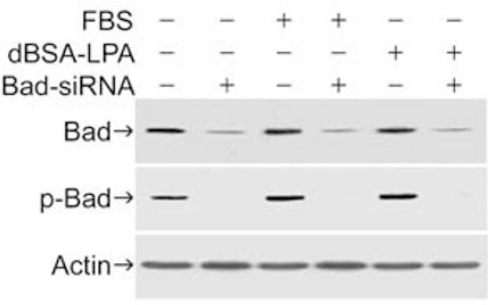

d

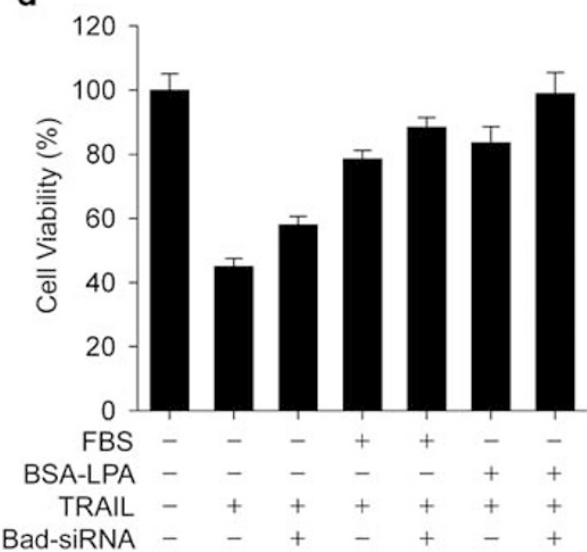

Figure 8 Knockdown of cFLIP or Bad by siRNA prevents TRAIL-induced cell death. HeLa cells were transfected with siRNAs of cFLIP or Bad for $12 \mathrm{~h}$ and recovered in fresh medium containing $10 \%$ FBS. After $24 \mathrm{~h}$, cells were cultured in serum-free media for $6 \mathrm{~h}$ and further incubated in the presence or absence of $10 \% \mathrm{FBS}$ for $6 \mathrm{~h}$. Cells were harvested and lysed by three cycles of freeze and thaw. Cytosolic proteins were separated by SDS-PAGE. The protein levels of cFLIP (a) and Bad (c) were determined by Western blot analyses. Cells were transfected with the siRNAs of cFLIP (b) or Bad (d) for $12 \mathrm{~h}$ and recovered in fresh medium containing $10 \%$ FBS. The cells were further cultured in serum-free medium for another $6 \mathrm{~h}$ and then treated with TRAlL in the presence or absence of $10 \% \mathrm{FBS}$ for $8 \mathrm{~h}$. Cell viability was determined by crystal violet staining. Data shown are the mean \pm S.D. of more than three independent experiments. ${ }^{* *} P<0.05$

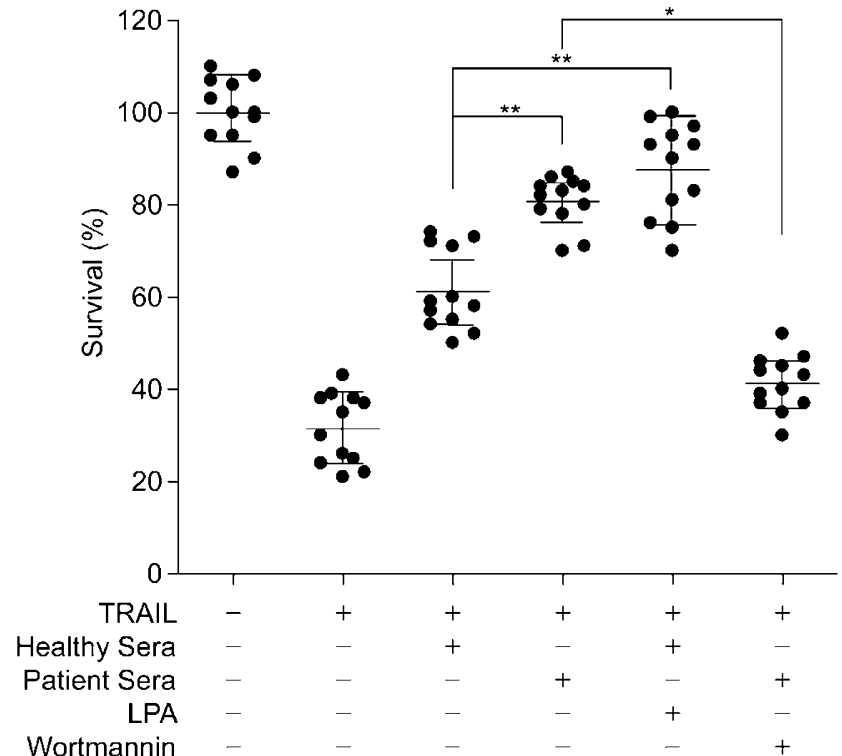

Figure 9 Sera from ovarian cancer patients prevent TRAIL-induced cell death. HeLa cells were treated with TRAIL in the presence or absence of sera from ovarian cancer patient and healthy donors, LPA $(1 \mu \mathrm{M})$, or Wortmannin $(40 \mathrm{nM})$ for $8 \mathrm{~h}$. The cells were washed with fresh medium, replated in $100-\mathrm{mm}$ culture dishes, and then cultured in fresh medium containing $10 \%$ FBS for an additional 2-week period. The plates were stained with crystal violet, and the number of colonies was counted. Data shown are the mean \pm S.D. of more than three independent experiments. ${ }^{*} P<0.01$ and ${ }^{* \star} P<0.05$
Bad expression. These results suggest that LPA and S1P are extracellular nonpeptide serum survival factors that may inhibit tumor cell apoptosis induced by TRAIL through the activation of PI3K/Akt survival pathway. Indeed, our data demonstrated that the sera from patients with ovarian cancer, which constitutively synthesizes and releases significant amounts of LPA, ${ }^{34}$ were more protective against TRAILinduced apoptosis than those from healthy donors, and the protection was suppressed by PI3K inhibitor. Thus, the serum level of lysophospholipids can be an important factor for therapy of cancer patients with TRAIL.

TRAIL is known to induce apoptosis in a variety of tumor cells. Preclinical studies in rodents and nonhuman primates have demonstrated that repeated systemic administration of TRAIL induces antitumor activity without detectable toxic side effects. ${ }^{36,37}$ However, not all tumor cells are sensitive to TRAIL-induced apoptosis. This lack of sensitivity may be attributed either to an unfavorable ratio of death to decoy receptors or to expression of resistant genes. ${ }^{3,31}$ So far, the majority of normal human cells tested appear to be relatively TRAIL resistant; however, recent experiments have demonstrated that cultured human liver cells may be sensitive to TRAIL-induced apoptosis. ${ }^{10}$ This discrepancy may be due to different serum concentrations used. ${ }^{10,11}$ We demonstrated that TRAIL-mediated tumor cell apoptosis was inhibited by a dose-dependent manner by increasing serum concentrations (Figure 1a). The major component in serum that suppressed 
TRAIL-induced apoptosis was found to be albumin. In addition, we found that albumins isolated from rat, horse, and human showed similar antiapoptotic effects, indicating that the source of albumin is not a critical factor for inducing an antiapoptotic signal cascade.

Albumin is a major serum protein that functions as a carrier with high affinity to lysophospholipids such as LPA and S1P within the bloodstream. ${ }^{12,19}$ Albumin serves two functions for bioactive LPA and S1P, which have pleiotropic functions such as mitogenesis and antiapoptosis. ${ }^{38}$ First, albumin acts as a carrier to solubilize them, without affecting their biologic activities. $^{12}$ Second, albumin increases their physiological half-lives by protecting them from degradation by phospholipases. ${ }^{39}$ Since normal serum contains about $5 \%$ albumin, $10 \% \mathrm{FBS}$ used in this study is equal to a concentration of $0.5 \%$ albumin. Our results showed that the protective effect of $5 \%$ albumin was similar to that of $10 \%$ FBS, indicating that the effect of FBS is about 10-fold higher than that of BSA. It suggests that bioactive lipid components bound to BSA used in this study may be oxidized or lost during preparation or storage. Indeed, the level of malondialdehyde, as a lipid peroxidation product, was significantly higher in BSA (Sigma, $0.23 \pm 0.03 \mu \mathrm{mol} / \mathrm{mg}$ protein) used in this experiment than freshly isolated BSA $(0.14 \pm 0.02 \mu \mathrm{mol} / \mathrm{mg}$ protein). In addition, our results showed that BSA, but not dBSA, prevented apoptotic cell death (Figure $1 \mathrm{~b}$ and $\mathrm{c}$ ). These data suggest that albumin-bound lipid components are responsible for the antiapoptotic effect of albumin. Moreover, we found that dBSA-LPA and dBSA-S1P, but not dBSA alone, protected HeLa cells from apoptosis induced by TRAIL in serum-free medium (Figure $2 b-d$ ). These results suggest that albuminbound bioactive LPA and S1P may account for the antiapoptotic activity of serum against TRAIL-induced apoptosis. However, involvement of other serum-surviving factors, such as growth factors and hormones, cannot be completely excluded.

LPA and S1P are produced in platelets, fibroblast, adipocytes, and tumor cells and secreted into biological fluids. LPA binds predominantly to the cell surface receptors EDG2, EDG3, and EDG7, while S1P is more specific to EDG1, EDG3, EDG5, and EDG8. ${ }^{15}$ They exert diverse effects such as platelet aggregation, cell differentiation, tumor invasion, angiogenesis, cell survival, and proliferation. ${ }^{21,40}$ By inhibiting apical caspase-8 activation and mitochondrial cytochrome $c$ release, LPA and S1P are potent antiapoptotic serum factors against TRAIL-induced apoptosis in HeLa as well as DLD-1 cells (Figure 1b and c), but not in MCF7 and HOS cells (data not shown). HeLa cells express predominantly EDG2, EDG4, and EDG7 receptors that induce LPA-mediated intracellular signal pathway, while MCF cells express low levels of these receptors and do not effectively respond to LPA. ${ }^{16}$ This cellline-specific response is likely linked to the degree of their receptor expression. Interestingly, serum LPA levels are significantly higher in cancer patients than in normal controls. ${ }^{41}$ We found that the sera from patients with ovarian cancer, which synthesizes significant amounts of LPA, ${ }^{34,41}$ showed more protective effects on TRAIL-induced cell death than those from healthy donors. Tumor cells capable of LPA production can increase their resistance to apoptosis induced by chemotherapeutic drugs ${ }^{42,43}$ and may also be protected from TRAIL-induced apoptosis by these mechanisms. Therefore, in therapeutic treatments of cancer patients with TRAIL or other antitumor drugs, the serum level of LPA generated from tumors or inflammatory cells should be considered.

LPA and S1P have been demonstrated to bind specific Gprotein-coupled EDG receptors, ${ }^{44}$ which activate the intracellular signaling event of PI3K-dependent activation of Akt. ${ }^{16,45}$ We showed that HeLa cells cultured with dBSA-LPA increased the activation of PI3K/Akt survival pathway compared with untreated control cells. Our data also showed that PTX-sensitive $G_{i / o}$ coupled to LPA-specific G-proteincoupled EDG2 may be involved in LPA-mediated activation of PI3K/Akt pathway (Figure 4c). Signals transduced from activated Akt have been shown to be sufficient for the prevention of apoptosis or the promotion of cell survival through phosphorylation of several proteins including proapoptotic $\mathrm{Bad}^{25}$ as well as through upregulation of cFLIP expression. ${ }^{33}$ Bad heterodimerizes with $\mathrm{Bcl}-\mathrm{X}_{\mathrm{L}}$ or $\mathrm{Bcl}-2$ and then promotes mitochondrial cytochrome $c$ release and caspase- 9 activation. Phosphorylated Bad binds to cytosolic protein 14-3-3, rather than to mitochondrial $\mathrm{Bcl}-2$ or $\mathrm{Bcl}-\mathrm{X}_{\mathrm{L}}$, preventing cytochrome $c$ release. ${ }^{30}$ Although Bad is known to regulate intrinsic death machinery, ${ }^{32}$ it has been demonstrated that Bad phosphorylation can prevent TNF- $\alpha$-induced apoptosis. ${ }^{31}$ Furthermore, the upregulation of Bad expression enhanced TRAIL-induced apoptosis, and the suppression of Bad phosphorylation by siRNA of PKA1, a kinase that phosphorylates Bad in some systems, prevented TRAILinduced apoptosis. ${ }^{46}$ Consistent with these observations, our data showed that FBS and dBSA-LPA increased Bad phosphorylation, resulting in suppression of the translocation of cytosolic Bad to mitochondria and mitochondrial cytochrome $c$ release (Figure 5). cFLIP is structurally similar to procaspase-8 in that it contains similar death effector domains and a caspase-like domain. However, cFLIP lacks the cysteine within the active site essential for the catalytic activity of caspase-8. Thus, cFLIP acts as a competitive inhibitor of caspase- 8 in the formation of the death-inducing signaling complex, which subsequently blocks apical caspase- 8 activation. ${ }^{47}$ Our data showed that FBS and dBSALPA increased cellular cFLIP expression and thus suppressed caspase-8 activation/activity (Figure 6). Increase in cFLIP level by dBSA-LPA was blocked by the transcription inhibitor ActD and the PI3K inhibitor LY294002, indicating that the increased level of cFLIP by LPA was regulated at the transcriptional step by PI3K/Akt pathway. Furthermore, the important role of Akt and cFLIP in antiapoptotic signal pathway elicited by serum and ABSA-LPA was demonstrated using molecular approaches of stable transfection with Akt and cFLIP genes (Figure 7). Indeed, overexpression of DNAkt abrogated the antiapoptotic effects of FBS and dBSALPA, and transfection with WT-Akt or CFLIP reduced TRAILinduced apoptosis, indicating that Akt activation is one of the critical mediators for the antiapoptotic effect of LPA. Taken together, our results indicate that Akt-dependent cFLIP expression and Bad phosphorylation are common mediators of antiapoptotic signal pathway of serum and albumin-bound LPA. Our results further suggest that LPA is an important factor for antiapoptotic effect of serum. 
It has recently been demonstrated that 21-base-pair double-stranded RNA (siRNA) is a potent mediator of the RNA interference effect, which specifically downregulates target gene expression in mammalian cells. We used this strategy to identify the functional roles of cFLIP and Bad in the antiapoptotic effect of serum on TRAIL-induced apoptosis. Our results indicate that specific knockdown of cFLIP by transfection with cFLIP siRNA effectively inhibited serum- and LPA-mediated protection against TRAIL-induced HeLa cell apoptosis (Figure 8b). Transfection with Bad siRNA prevented cells from TRAIL-induced apoptosis in the presence or absence of serum or LPA (Figure $8 \mathrm{~d}$ ). These results indicate the involvement of cFLIP upregulation and Bad phosphorylation in LPA-induced protection from TRAIL-induced apoptosis. However, cFLIP upregulation is a more crucial factor than Bad phosphorylation in the survival signal pathway against TRAIL-induced apoptosis.

We here present evidence that the albumin-bound LPA and $\mathrm{S1P}$ act as extracellular mediators responsible for regulation of major antiapoptotic factors that prevent tumor cells from apoptosis induced by TRAIL. Most known serum survival factors are polypeptide growth factors or hormones such as PDGF, EGF, IGF-1, and insulin. These serum survival factors, with the exception of PDGF and IGF-1, occur at concentrations far below those necessary to elicit survival effects. LPA and S1P showed maximal antiapoptotic effects at 4 and $0.4 \mu \mathrm{M}$, respectively (Figure $2 \mathrm{a}$ ). These concentrations are pathophysiologically relevant, since their levels in serum range from 2 to 28 and 0.2 to $0.5 \mu \mathrm{M}$, respectively. ${ }^{48,49}$ Since LPA concentrations attaining $28 \mu \mathrm{M}$ were reported in FBS, ${ }^{50}$ medium containing $10 \%$ FBS used in this study was equal to $2.8 \mu \mathrm{M}$ of LPA, which significantly protected cells from TRAILinduced apoptosis (Figure 1). However, plasma levels of LPA from healthy individuals are relatively low, approximately $0.5 \mu \mathrm{M} .{ }^{41,51}$ However, its concentration was elevated to more than 4- to 60-fold in plasma samples from cancer patients but not all the patients, and this concentration is correlated with the degree of cancer malignancy. ${ }^{35}$ Therefore, antiapoptotic concentration of LPA $(1-4 \mu \mathrm{M})$ used in this study was lower than plasma levels $(\sim 8 \mu \mathrm{M})$ in cancer patients. ${ }^{41}$ Here, we showed that sera from patients with ovarian cancer, which synthesizes significant amounts of LPA, ${ }^{35}$ possessed more protective effect against TRAIL-induced apoptosis than those from healthy donors (Figure 9). These data suggest that altering production or metabolism of LPA and S1P may provide an additional strategy to develop cancer therapy with TRAIL or other anticancer drugs. However, it cannot completely exclude the possibility that other antiapoptotic phospholipid mediators including shingosylphosphorylcholine, which is present at the level of $\sim 0.1 \mu \mathrm{M}$ in serum, ${ }^{52}$ may be involved in antiapoptotic effect of serum.

In conclusion, we demonstrated that a possible molecular mechanism for the antiapoptotic effects of the serum components LPA and S1P is to suppress TRAIL-induced caspase- 8 activation and mitochondrial cytochrome $c$ release by increases in cFLIP expression and Bad phosphorylation, which were critically dependent upon the activation of the PI3K/Akt signal pathway. These findings suggest that the suppression of lysophospholipid synthesis in tumors or immune cells represents a potential target to improve therapy of cancer patients with TRAIL or other cancer therapeutic drugs.

\section{Materials and Methods}

\section{Materials}

Dulbecco's modified Eagle's medium (DMEM), FBS, penicillin, streptomycin, and L-glutamate were purchased from Life Technologies (Gaithersburg, MD, USA). Dimethyl sulfoxide, actin antibody, Wortmannin, and LY294002 were purchased from Calbiochem (La Jolla, CA, USA). Cytochrome $c$ antibody (556432) and caspase-8 antibody (66231A) were obtained from PharMingen (San Diego, CA, USA). Polyclonal caspase-3 antibody $(\mathrm{H}-277)$ and cFLIP antibody $(\mathrm{H}-202)$ were purchased from Santa Cruz Biotechnology (Santa Cruz, CA, USA). Antibody for phospho-specific Akt (Ser-473) was obtained from Transduction Laboratories (Lexington, KY, USA). Cytochrome coxidase subunit IV (COX IV) was purchased from Molecular Probes (Eugene, OR, USA). Ac-DEVD-pNA and Ac-IETD-pNA were obtained from Alexis Corporation (San Diego, CA, USA). PTX was purchased from Calbiochem (La Jolla, CA, USA). BSA, dBSA (Fraction V), S1P, and LPA were purchased from Sigma (St. Louis, MO, USA). dBSA reconstituted with LPA (dBSA-LPA) or S1P (dBSA-S1P) was prepared by mixing $5 \% \mathrm{dBSA}$ solution in calcium and magnesium-free phosphatebuffered saline (PBS) with LPA or S1P. The solutions were made fresh for each experiment. Blood samples were drawn from 12 ovarian cancer patients (aged 32-58 years) and 12 healthy female donors (aged 30-55 years). The blood was clotted at $4-8^{\circ} \mathrm{C}$, and sera were subsequently prepared by centrifugation at $3000 \times g$ for $40 \mathrm{~min}$.

\section{Cell culture}

The human tumor cell lines, HeLa (cervical carcinoma), DLD-1 (colon cancer), HOS (prostate cancer), and MCF-7 (breast cancer), were purchased from American Type Culture Collection. Cells were cultured in DMEM supplemented with $10 \%$ FBS, $2 \mathrm{mM} \mathrm{L-glutamine,} 100 \mathrm{U} / \mathrm{ml}$ penicillin, $100 \mathrm{U} / \mathrm{ml}$ streptomycin, and $5 \mathrm{mM} \mathrm{HEPES}$ at $37^{\circ} \mathrm{C}$ in $95 \%$ air/ $5 \% \mathrm{CO}_{2}$. HeLa cells were transfected with empty vector (pcDNA3)_or vector containing WT-Akt, DN-Akt (K179M,) or cFLIP using lipofectamine (Life Technologies Inc.). Clonal selection was conducted by culturing with G418 $(800 \mu \mathrm{g} / \mathrm{ml})$, followed by serial dilution of the cells in 96-well plates. Stable transfectant clones with high expression of the target genes were identified by Western blot analysis.

\section{Cell viability}

Cell viability was determined by the crystal violet staining method, as described previously. ${ }^{53}$ In brief, cells plated in 12-well dishes at a density of $1 \times 10^{6} \mathrm{cell} / \mathrm{ml}$ were cultured for $8 \mathrm{~h}$ in $10 \%$ FBS containing DMEM overnight and further cultured in serum-free medium for another $6 \mathrm{~h}$. Cells were treated with TRAIL $(100 \mathrm{ng} / \mathrm{ml})$ in the presence or absence of FBS, albumin, dBSA-LPA, or dBSA-S1P. After $8 \mathrm{~h}$ incubation, viable cells were stained with $0.5 \%$ crystal violet in $30 \%$ ethanol and $3 \%$ formaldehyde for $10 \mathrm{~min}$ at room temperature. Plates were then washed four times with tap water. After drying, cells were lysed with $1 \%$ SDS solution, and dye uptake was measured at $550 \mathrm{~nm}$ using a 96-well plate reader. Cell viability was calculated from relative dye intensity compared with untreated samples. For a long-term assay for cell viability, clonogenic assay was used. In brief, HeLa cells were treated with $100 \mathrm{ng} / \mathrm{ml}$ TRAIL in the presence or absence of human serum for $8 \mathrm{~h}$. The cells were washed with fresh medium, replated in 100-mm culture dishes, and then cultured in fresh medium 
containing 10\% FBS for an additional 2-week period. The plates were stained with crystal violet, and the number of colonies was counted.

\section{Western blot analysis}

Cells were harvested, washed twice with ice-cold PBS, and resuspended in $20 \mathrm{mM}$ Tris- $\mathrm{HCl}$ buffer ( $\mathrm{pH} 7.4)$ containing a protease inhibitor mixture $(0.1 \mathrm{mM}$ phenylmethylsulfonyl fluoride, $5 \mu \mathrm{g} / \mathrm{ml}$ pepstatin, and $1 \mu \mathrm{g} / \mathrm{ml}$ chymostatin). Cells were lysed by three cycles of freeze and thaw, and cytosolic fractions were obtained by centrifugation at $120000 \times g$ for $20 \mathrm{~min}$. Cytosolic proteins $(20 \mu \mathrm{g})$ were separated on SDS-PAGE and transferred to nitrocellulose membranes. The membranes were hybridized with antibodies against caspase-3, caspase-8, cFLIP, p-Akt, and Akt, and protein bands were visualized by exposure to an X-ray film.

\section{Transfection with siRNA}

The target sequences of siRNAs for CFLIP and Bad are $5^{\prime}$ AAGTAAAGAACAAAGACTTAACCTGTCTC-3' and 5'-AAGAAGGGACTTCCTCGCCCG-3', respectively. HeLa cells were transfected with these double-stranded siRNAs $(40 \mathrm{nmol} / \mathrm{ml})$ for $12 \mathrm{~h}$ by lipofectamine method according to the manufacturer's protocol (Life Technologies Inc.) and recovered in fresh media containing $10 \%$ FBS for $24 \mathrm{~h}$. The cells were cultured in serum-free media for $6 \mathrm{~h}$ and then treated with TRAIL in the presence or absence of FBS or dBSA-LPA. The protein levels of cFLIP and Bad were analyzed by Western blot analysis, and cell viability was determined by crystal violet staining.

\section{Detection of cytochrome $c$ release}

Cells were incubated with TRAIL $(100 \mathrm{ng} / \mathrm{ml})$ for the indicated times, harvested, and resuspended in ice-cold mitochondrial fractionation buffer (20 mM HEPES, $1 \mathrm{mM}$ sodium EDTA, $10 \mathrm{mM} \mathrm{KCl}, 1 \mathrm{mM}$ DTT, $10 \mu \mathrm{M}$ aprotinin, $10 \mathrm{mM}$ phenylmethylsulfonyl fluoride, and $250 \mathrm{mM}$ sucrose). After homogenization using a Dounce homogenizer, cytosolic fractions were obtained by centrifugation at $12000 \times g$ for $20 \mathrm{~min}$ at $4^{\circ} \mathrm{C}$. The cytosolic proteins $(40 \mu \mathrm{g})$ were loaded onto a $12 \%$ SDS-PAGE and transferred to nitrocellulose membrane. Western blotting was performed using a cytochrome $c$ antibody to determine mitochondrial cytochrome $c$ release.

\section{DNA fragmentation assay}

Cells were harvested using a plastic scraper and washed with PBS by centrifugation at maximum speed in a microcentrifuge for $30 \mathrm{~s}$ at $4^{\circ} \mathrm{C}$. Cells were lysed in lysis solution (0.5\% SDS, $10 \mathrm{mM}$ EDTA, $0.5 \mathrm{mg} / \mathrm{ml}$ proteinase $\mathrm{K}$, and $50 \mathrm{mM}$ Tris- $\mathrm{HCl}, \mathrm{pH} 8.0$ ). DNA was extracted with a standard phenol-chloroform method and precipitated with cold ethanol. The pellets were dried and resuspended in $100 \mu \mathrm{l}$ of $20 \mathrm{mM}$ Tris- $\mathrm{HCl}, \mathrm{pH}$ 8.0. After digesting RNA with RNase $(0.1 \mathrm{mg} / \mathrm{ml})$ at $37^{\circ} \mathrm{C}$ for $1 \mathrm{~h}$, samples $(15 \mu \mathrm{l})$ were electrophoresed through a $1.2 \%$ agarose gel in $450 \mathrm{mM}$ Tris borate-EDTA buffer, pH 8.0. DNA was photographed under visualization with UV light.

\section{4,6-Diamidino-2-phenylindole staining of nuclei}

Morphological changes in the nuclear chromatin in cells undergoing apoptosis were detected by staining with the DNA binding fluorochrome 4,6-diamidino-2-phenylindole (DAPI). HeLa cells were grown on glass coverslips and treated with TRAIL in the absence or presence of serum components for $5 \mathrm{~h}$. Cells were washed twice with PBS and fixed by incubation in $4 \%$ paraformaldehyde for $30 \mathrm{~min}$. Following washes with PBS, cells were incubated in $1 \mu \mathrm{g} / \mathrm{ml}$ DAPI solution for $30 \mathrm{~min}$ in the dark. Coverslips were then washed with PBS and analyzed by fluorescence microscopy.

\section{Determination of caspase activity and lipid peroxidation}

The cell pellets were washed with ice-cold PBS and resuspended in $100 \mathrm{mM}$ HEPES buffer, $\mathrm{pH} 7.4$, containing a protease inhibitor mixture $(5 \mathrm{mg} / \mathrm{ml}$ aprotinin and pepstatin, $10 \mathrm{mg} / \mathrm{ml}$ leupeptin, and $0.5 \mathrm{mM}$ phenylmethylsulfonyl fluoride). The cell suspension was lysed by three freeze-thaw cycles, and the cytosolic fraction was obtained by centrifugation at $12000 \times g$ for $10 \mathrm{~min}$ at $4^{\circ} \mathrm{C}$. Caspase activity was determined by measuring proteolytic cleavage of the chromogenic substrate Ac-DEVD-pNA (caspase-3-like activity) or Ac-IETD-pNA (caspase-8-like activity) as described previously. ${ }^{54}$ The lipid peroxidation product malondialdehyde was measured as thiobarbituric acid-reactive substance as previously described. ${ }^{55}$

\section{Data analysis and statistics}

The data are presented as the means \pm S.D. from more than three independent experiments. Statistical comparisons between groups were performed using the Student's $t$-test.

\section{Acknowledgements}

This work was supported by Vascular System Research Center grant from Korea Science and Engineering Foundation. We thank Dr. Peter K Kim (University of Pittsburgh) and Mrs. Elaine Por for helpful comments and critical reading of the manuscript.

\section{References}

1. Wiley SR, Schooley K and Smolak PJ (1995) Identification and characterization of a new member of the TNF family that induces apoptosis. Immunity 3: 673682

2. Pitt RM, Marsters SA, Ruppert TS, Donahne CJ, Moore A and Ashkenazi A (1996) Induction of apoptosis by Apo-2 ligand, a new member of the tumor necrosis factor cytokine family. J. Biol. Chem. 271: 12687-12690

3. Ashkenazi A and Dixit VM (1998) Death receptors: signaling and modulation. Science 281: 1305-1308

4. Ashkenazi A and Dixit VM (1999) Apoptosis control by death and decoy receptors. Curr. Opin. Cell Biol. 11: 255-260

5. Chao DT and Korsmeyer SJ (1998) BCL-2 family: regulators of cell death. Annu. Rev. Immunol. 16: 395-419

6. Irmler M, Thome M, Schneider P and Hofmann K (1997) Inhibition of death receptor signals by cellular FLIP. Nature 10: 190-195

7. Wang CY, Mayo MW, Korneluk RG, Goeddel DV and Baldwin Jr. AS (1998) NF-kappaB antiapoptosis: induction of TRAF1 and TRAF2 and c-IAP1 and cIAP2 to suppress caspase-8 activation. Science 28: 1680-1683

8. Gibson EM, Henson ES, Haney N, Villanueva J and Gibson SB (2002) Epidermal growth factor protects epithelial-derived cells from tumor necrosis factor-related apoptosis-inducing ligand-induced apoptosis by inhibiting cytochrome $c$ release. Cancer Res. 62: 488-496

9. Kothny-Wilkes G, Kulms D, Luger TA, Kubin M and Schwarz T (1998) Interleukin-1 protects transformed keratinocytes from tumor necrosis factorrelated apoptosis-inducing ligand. J. Biol. Chem. 273: 29247-29253 
10. Jo M, Kim TH, Seol, Esplen JE, Dorko K, Billiar TR and Strom SC (2000) Apoptosis induced in normal human hepatocytes by tumor necrosis factorrelated apoptosis-inducing ligand. Nat. Med. 6: 564-567

11. Lawrence D, Shahrokh Z, Marsters S and Ashkenazi A (2001) Differential hepatocyte toxicity of recombinant Apo2L/TRAIL versions. Nat. Med. 7: 383385

12. Tigyi $G$ and Miledi $R$ (1992) Lysophosphatidates bound to serum albumin activate membrane currents in Xenopus oocytes and neurite retraction in PC12 pheochromocytoma cells. J. Biol. Chem. 267: 21360-21367

13. Gaits F, Fourcade $O$ and Le Balle F (1997) Lysophosphatidic acid as a phospholipid mediator: pathways of synthesis. FEBS Lett. 410: 54-58

14. Fang X, Schummer M and Mao M (2002) Lysophosphatidic acid is a bioactive mediator in ovarian cancer. Biochim. Biophys. Acta 1582: 257-264

15. Svetlov SI, Sautin YY and Crawford JM (2002) EDG receptors and hepatic pathophysiology of LPA and S1P: EDG-ology of liver injury. Biochim. Biophys. Acta 1582: 251-256

16. Baudhuin LM, Cristina KL, Lu J and Xu Y (2002) Akt activation induced by lysophosphatidic acid and sphingosine-1-phosphate requires both mitogenactivated protein kinase kinase and p38 mitogen-activated protein kinase and is cell-line specific. Mol. Pharmacol. 62: 660-671

17. Khwaja A (1999) Akt is more than just a Bad kinase. Nature 401: 33-34

18. Kobayashi T, Tanaka-Ishii $R$, Taguchi $R$, Ikezawa $H$ and Murakami-Murofushi $K$ (1999) Existence of a bioactive lipid, cyclic phosphatidic acid, bound to human serum albumin. Life Sci. 65: 2185-2191

19. Thumser AE, Voysey JE and Wilton DC (1994) The binding of lysophospholipids to rat liver fatty acid-binding protein and albumin. Biochem. J. 301: 801-806

20. Goetzl EJ and An S (1998) Diversity of cellular receptors and functions for the lysophospholipid growth factors lysophosphatidic acid and sphingosine-1phosphate. FASEB J. 12: 1589-1598

21. Le Stunff H, Peterson C, Liu H, Milstien S and Spiegel S (2002) Sphingosine-1phosphate and lipid phosphohydrolases. Biochim. Biophys. Acta 23: 8-17

22. Johnstone RW, Ruefli AA and Lowe SW (2002) Apoptosis: a link between cancer genetics and chemotherapy. Cell 108: 153-164

23. Cohen GM (1997) Caspases: the executioners of apoptosis. Biochem. J. 15: $1-16$

24. Crowder RJ and Freeman RS (1998) Phosphatidylinositol 3-kinase and Akt protein kinase are necessary and sufficient for the survival of nerve growth factor-dependent sympathetic neurons. J. Neurosci. 15: 2933-2943

25. Datta SD, Dudek H, Tao X, Masters S, Fu H, Gotoh Y and Greenberg ME (1997) Akt phosphorylation of BAD couples survival signals to the cell-intrinsic death machinery. Cell $91: 231-241$

26. Del Peso L, Gonzalez-Garcia M, Page C, Herrera and Nunez G (1997) Interleukin-3-induced phosphorylation of BAD through the protein kinase Akt. Science 24: 687-689

27. Hawes BE, Luttrell LM, van Biesen T and Lefkowitz RJ (1996) Phosphatidylinositol 3-kinase is an early intermediate in the $\mathrm{G}_{\beta \gamma}$-mediated mitogen-activated protein kinase signaling pathway. J. Biol. Chem. 271: 12133-12136

28. Weiner JA and Chun J (1999) Schwann cell survival mediated by the signaling phospholipid lysophosphatidic acid. Proc. Natl. Acad. Sci. USA 96: 5233-5238

29. Yuan J and Yankner BA (2000) Apoptosis in the nervous system. Nature 407: 802-809

30. Kennedy SG, Kandel ES, Cross TK and Hay N (1999) Akt/protein kinase B inhibits cell death by preventing the release of cytochrome $c$ from mitochondria. Mol. Cell. Biol. 19: 5800-5810

31. Pastorino JG, Tafani M and Farber JL (1999) Tumor necrosis factor induces phosphorylation and translocation of BAD through a phosphatidylinositide-3OH kinase-dependent pathway. J. Biol. Chem. 274: 19411-19416

32. Datta SR, Dudek H, Tao X, Masters S, Fu H, Gotoh Y and Greenberg ME (1997) Akt phosphorylation of BAD couples survival signals to the cell-intrinsic death machinery. Cell 91: 231-241

33. Panka DJ, Mano T, Suhara T, Walsh K and Mier JW (2001) Phosphatidylinositol 3-kinase/Akt activity regulates c-FLIP expression in tumor cells. J. Biol. Chem. 276: 6893-6896

34. Eder AM, Sasagawa T, Mao M, Aoki J and Mills GB (2000) Constitutive and lysophosphatidic acid (LPA)-induced LPA production: role of phospholipase $D$ and phospholipase A2. Clin. Cancer Res. 6: 2482-2491
35. Xu Y, Shen Z, Wiper DW, Wu M, Morton RE, Elson P, Kennedy AW, Belinson J, Markman M and Casey G (1998) Lysophosphatidic acid as a potential biomarker for ovarian and other gynecologic cancers. JAMA 280: 719-723

36. Ashkenazi A, Pai RC, Fong S, Leung S and Lawrence DA (1999) Safety and antitumor activity of recombinant soluble Apo2 ligand. J. Clin. Invest. 104 $155-162$

37. Walczak H, Miller RE, Ariail K and Lynch DH (1999) Tumoricidal activity of tumor necrosis factor-related apoptosis-inducing ligand in vivo. Nat. Med. 5: 157-163

38. Chun J, Goetzl EJ, Hla T, Igarashi Y, Lynch KR, Moolenaar W, Pyne S and Tigyi G (2002) International Union of Pharmacology. XXXIV. Lysophospholipid receptor nomenclature. Pharmacol. Rev. 54: 265-269

39. Jalink K, Hordijk PL and Moolenaar WH (1994) Growth factor-like effects of lysophosphatidic acid, a novel lipid mediator. Biochim. Biophys. Acta 1198: 185-196

40. Murakami-Murofushi $\mathrm{K}$ and Uchiyama $\mathrm{A}$ (2002) Biological functions of a novel lipid mediator, cyclic phosphatidic acid. Biochim. Biophys. Acta 1582: 1-7

41. Xu Y, Shen Z, Wiper DW, Wu M, Morton RE, Elson P, Kennedy AW, Belinson J, Markman M and Casey G (1998) Lysophosphatidic acid as a potential biomarker for ovarian and other gynecologic cancers. JAMA 26 : $719-723$

42. Sautin YY, Crawford JM and Svetlov SI (2001) Enhancement of survival by LPA via Erk1/Erk2 and PI3-kinase/Akt pathways in a murine hepatocyte cell line. Am. J. Physiol. Cell physiol. 281: C2010-C2019

43. Frankel A and Mills GB (1996) Peptide and lipid growth factors decrease cisdiaminedichloroplatinum-induced cell death in human ovarian cancer cells. Clin. Cancer Res. 2: 1307-1313

44. Goetzl EJ (2001) Pleiotypic mechanisms of cellular responses to biologically active lysophospholipids. Prostaglandins 64: 11-20

45. Koh JS, Lieberthal W, Heydrick S and Levine JS (1998) Lysophosphatidic acid is a major serum noncytokine survival factor for murine macrophages which acts via the phosphatidylinositol 3-kinase signaling pathway. J. Clin. Invest. 102: $716-727$

46. Aza-Blanc P, Cooper CL, Wagner K, Batalov S, Deveraux QL and Cooke MP (2003) Identification of modulators of TRAIL-induced apoptosis via RNAi-based phenotypic screening. Mol. Cell 12: 627-637

47. Krueger A, Schmitz I, Baumann S, Krammer PH and Kirchhoff S (2001) Cellular FLICE-inhibitory protein splice variants inhibit different steps of caspase-8 activation at the CD95 death-inducing signaling complex. J. Biol. Chem. 276: 20633-20640

48. Yatomi Y, Yamamura S, Ruan F and Igarashi $Y$ (1997) Sphingosine-1phosphate induces platelet activation through an extracellular action and shares a platelet surface receptor with lysophosphatidic acid. J. Biol. Chem. 272: 5291-5297

49. Yatomi $Y$, Ozaki $Y$, Ohmori $T$ and Igarashi $Y$ (2001) Sphingosine-1. phosphate: synthesis and release. Prostaglandins Other Lipid Mediat. 64: 107-122

50. Tokumura A, limori M, Nishioka $Y$, Kitahara M, Sakashita M and Tanaka S (1994) Lysophosphatidic acids induce proliferation of cultured vascular smooth muscle cells from rat aorta. Am. J. Physiol. 267: C204-C210

51. Sasagawa T, Suzuki K, Shiota T, Kondo T and Okita M (1998) The significance of plasma lysophospholipids in patients with renal failure on hemodialysis. J. Nutr. Sci. Vitaminol. (Tokyo) 44: 809-818

52. Meyer zu Heringdorf D, Himmel HM and Jakobs KH (2002) Sphingosylphosphorylcholine - biological functions and mechanisms of action. Biochim. Biophys. Acta 23: 178-189

53. Kim YM, Talanian RV and Billiar TR (1997) Nitric oxide inhibits apoptosis by preventing increases in caspase-3-like activity via two distinct mechanisms. J. Biol. Chem. 272: 31138-31148

54. Kim YM, Kim TH, Chung HT, Talanian RV, Yin XM and Billiar TR (2000) Nitric oxide prevents tumor necrosis factor alpha-induced rat hepatocyte apoptosis by the interruption of mitochondrial apoptotic signaling through S-nitrosylation of caspase-8. Hepatology 32: 770-778

55. Kim YM, de Vera ME, Watkins SC and Billiar TR (1997) Nitric oxide protects cultured rat hepatocytes from tumor necrosis factor- $\alpha$-induced apoptosis by inducing heat shock protein 70 expression. J. Biol. Chem. 272: $1402-1411$ 